\title{
A clinical and epidemiological study of non-venereal genital dermatoses: A cross-sectional, hospital-based study from Nepal
}

\author{
Vikash Paudel ${ }^{1,2}$, Deepa Chudal ${ }^{3}$, Upama Paudel2, Dwarika Prasad Shrestha² \\ ${ }^{1}$ Department of Dermatology, National Medical College, Birgunj, Parsa, Nepal ${ }^{2}$ Department of Dermatology and \\ Venereology, Institute of Medicine, Maharajgunj Medical Campus, Kathmandu, Nepal ${ }^{3}$ Deputy Superintendent of Police, \\ Nepal Police Hospital, Kathmandu, Nepal
}

Corresponding author: Vikash Paudel, MD, E-mail: vikashpoudel@iom.edu.np

\begin{abstract}
Background: Non-venereal genital dermatoses are the conditions of the genitalia that are not transmitted sexually. They may be confused with venereal diseases and be responsible for concerns among patients as well as diagnostic dilemmas for physicians. This study was conducted to determine the prevalence and describe the patterns of non-venereal genital conditions. Methods: This was a hospital-based, cross-sectional, prospective study conducted in a tertiary center in Kathmandu, Nepal, over a period of one year. Non-probability purposive sampling was employed to select the samples. Two hundred patients were enrolled in the study. Ethical approval was taken prior to the study. Detailed history taking along with a complete cutaneous examination were conducted for all patients and recorded in a preformed proforma. Results: Among 21366 patients, two hundred patients had non-venereal genital dermatoses. The prevalence of non-venereal dermatoses was $0.93 \%$. The mean age of the patient was $29.5 \pm 15$ years, ranging from 2 months to 81 years. The male-to-female ratio was 2.7:1. Itching was the most common presentation (46\%). Fifty-four different types of non-venereal diseases were encountered and classified into inflammatory lesions ( $\mathrm{n}=84 ; 42 \%)$, infections and infestations $(\mathrm{n}=43 ; 21.5 \%)$, normal variants and benign abnormalities ( $\mathrm{n}=41 ; 20.5 \%)$, and miscellaneous $(\mathrm{n}=21 ; 10.5 \%)$. The most common were, among inflammatory dermatoses, drug reactions $(11.5 \%)$ and eczema $(6.5 \%)$ and, among infections and infestations, scabies (9.5\%) and fungal infections (7.5\%). Conclusion: Non-venereal genital dermatoses are important yet less common dermatological conditions. A number of patients have misconceptions about them as venereal. A comprehensive study of non-venereal dermatological genital conditions is required for careful management to minimize morbidity.
\end{abstract}

Key words: dermatoses; genital dermatosis; non-venereal

\section{INTRODUCTION}

Genital dermatoses are less common dermatoses, yet bear significant importance in personal well-being. Non-venereal genital dermatoses are conditions that are not transmitted sexually and without the role of venereal agents [1]. As the skin homeostasis around the ano-genitalia is related to reproduction, excretion, and digestion, its dermatosis might be related to skin pathophysiology and sexual, urinary, or digestive dysfunction [2].
Genital dermatoses pose serious diagnostic and therapeutic challenges due to privacy, hesitant checkups, embarrassment, and the inability of necessary investigations [3]. These dermatoses may also lead to mental distress with the feeling of guilt and, if not treated properly in time, may lead to complications as well $[1,4]$. A number of patients with genital dermatoses may visit gynecological, urological, surgical, or other super-specialties in which exposure to dermatological disorders is minimal $[5,6]$. Very few studies from Nepal have investigated the overall

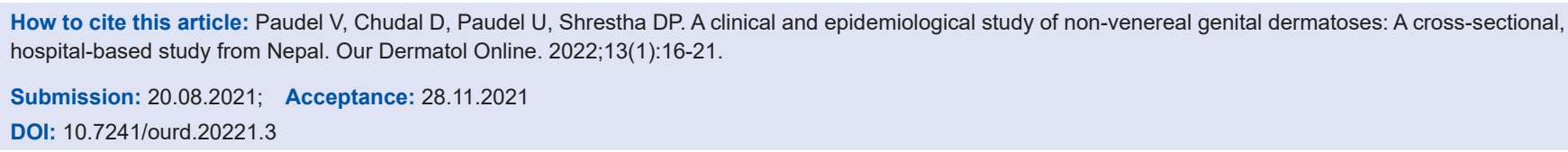


pattern of non-venereal genital dermatoses [7-9]. Thus, we investigated the epidemiological patterns of nonvenereal genital dermatoses among patients presenting to a dermatology clinic.

\section{METHODS}

This was a hospital-based, cross-sectional, prospective study conducted in the Department of Dermatology of the Institute of Medicine, Tribhuvan University Teaching Hospital, Kathmandu, Nepal, over a period from June 2014 to May 2015. Ethical approval was taken from the Institutional Review Board (IRB Reference No. 6-1 1-E/071/072) prior to the study. Nonprobability purposive sampling was employed to select the samples. Two hundred patients were enrolled in the study. All participants provided written informed consent for participation. All patients with ano-genital lesions with no active venereal disease were included in the study. The diagnosis was based on detailed history taking, clinical features, and appropriate investigations. Findings from examination were noted and details were recorded in a prepared proforma. Statistical Package for Social Science (SPSS), version 20, was employed for statistical analysis. A chi-square test was employed to determine the level of significance. Descriptive statistics were employed to compute the mean and standard deviation. The results were considered statistically significant at an alpha of $5 \%$ ( $\mathrm{p} \leq 0.05)$.

\section{RESULTS}

\section{Demographic Data}

Among the total of 21366 patients studied, two hundred had non-venereal genital dermatoses. Thus, the hospital prevalence of non-venereal genital dermatoses was $0.93 \%$. The age of the patients ranged from 2 months to 81 years, with a mean of 29.5 years (SD 15.5 years); and a median and mode of 28 years. The most common age group was $21-30$ years ( $42 \%)$, followed by $31-40$ years (15\%), $11-20$ years $(12 \%)$, and $0-10$ years $(10.5 \%)$ (Table 1). The male-to-female ratio was 2.7:1. Table 1 shows the socio-demographic characteristics.

\section{Patterns of Clinical Complaints among the Patients}

The most common complaint was pruritus in both males and females, which was present in $46 \%$ of the patients. The other common symptoms were pain, blisters, swelling, burning, sores, and so forth. Around $10 \%$ of the patients were asymptomatic (Fig. 1).

\section{Clinical Patterns According to the Site of Involvement}

Non-venereal genital conditions were grouped into four types according to the sites affected: 1. genital, 2 . oro-genital, 3. genital, and other skin, 4. oral, genital and other skin sites (oro-genital and skin). In this study, genital lesions alone comprised 107 (53.5\%), followed by genital and other skin lesions comprising $56(28 \%)$, oro-genital and skin lesions comprising $30(15 \%)$ and oro-genital lesions comprising 7 (3.5\%). The involvement of the genitalia alone was found to be significantly higher than in other groups $(\mathrm{p}=0.02)$. Table 2 shows the patterns of the different diseases.

\section{Clinical Patterns According to Etiology}

According to etiological categories, the most common subtype of lesion was inflammatory in 83 patients (41.5\%), followed by infections in 47 patients $(23.5 \%)$,

\begin{tabular}{llcc}
$\begin{array}{l}\text { Table 1: Demographic characteristics of patients with } \\
\text { non-venereal genital dermatoses }\end{array}$ \\
\hline Characteristics & Total & $\mathbf{( n )}$ & $\mathbf{( \% )}$ \\
\cline { 2 - 3 } & & $\mathbf{2 0 0}$ & $\mathbf{1 0 0}$ \\
\hline Sex & Male & 146 & 73 \\
Age (yrs.) & Female & 54 & 27 \\
& $0-10$ & 21 & 10.5 \\
& $11-20$ & 24 & 12 \\
& $21-30$ & 84 & 42 \\
& $31-40$ & 30 & 15 \\
& $41-50$ & 20 & 10 \\
& $51-60$ & 12 & 6 \\
& $61-70$ & 7 & 3.5 \\
Marital status & $71+$ & 2 & 1 \\
& Married & 100 & 50 \\
& Unmarried & 99 & 49.5 \\
Occupation & Single & 1 & 0.5 \\
& Students & 66 & 33 \\
& Businessperson & 30 & 15 \\
& Serviceperson & 27 & 13.5 \\
& Housewives & 24 & 12 \\
& Farmers & 22 & 11 \\
& Dependents & 15 & 7.5 \\
& Others & 10 & 5 \\
\hline
\end{tabular}

Table 2: Patterns of genital and non-genital involvement in patients with non-venereal genital dermatoses

\begin{tabular}{|c|c|c|c|c|c|}
\hline \multirow[t]{2}{*}{ Distribution } & \multicolumn{2}{|c|}{ Sex } & \multirow{2}{*}{$\begin{array}{c}\text { Total } \\
(n=200)\end{array}$} & \multirow{2}{*}{$\begin{array}{c}\text { Percentage } \\
\text { (\%) }\end{array}$} & \multirow[t]{2}{*}{$p$ value } \\
\hline & $\mathbf{F}$ & M & & & \\
\hline Genital involvement & 25 & 82 & 107 & 53.5 & 0.02 \\
\hline $\begin{array}{l}\text { Genital and non-genital } \\
\text { involvement }\end{array}$ & 29 & 64 & 93 & 46.5 & \\
\hline Total & 54 & 146 & 200 & 100 & \\
\hline
\end{tabular}


www.odermatol.com

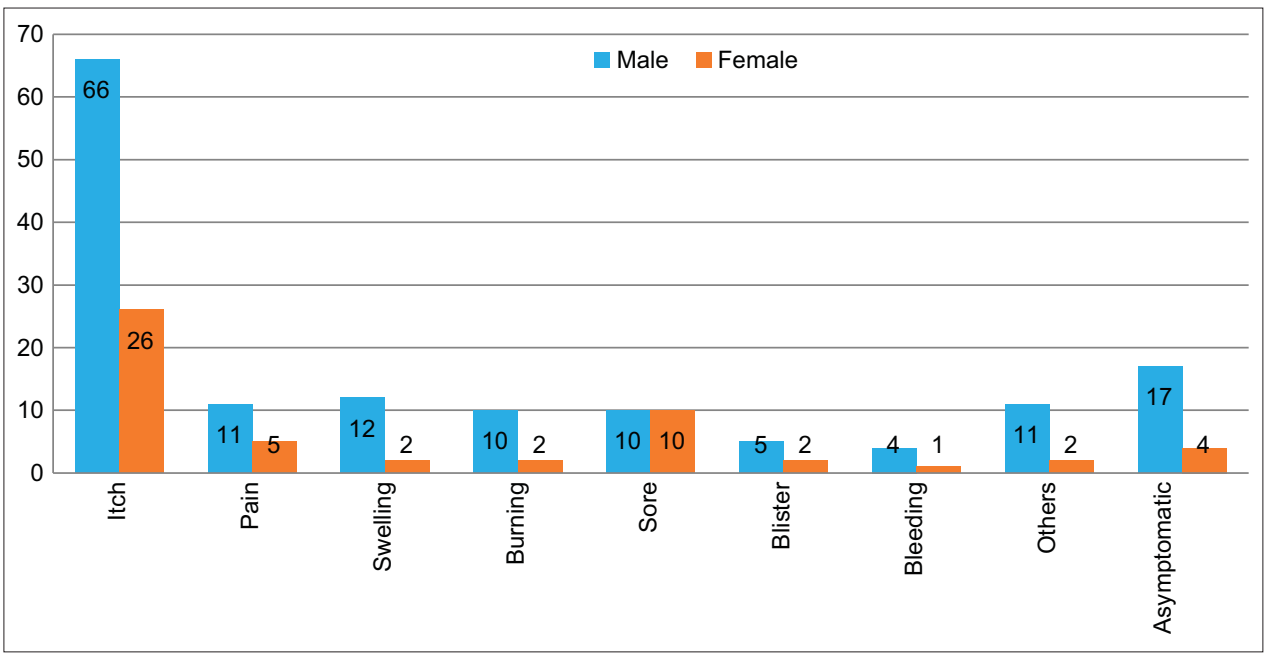

Figure 1: Common presenting complaints of the patients.

benign abnormalities in 44 patients $(22 \%)$, artefacts in 4 patients (2\%), premalignant or malignant lesions in 2 patients (1\%), congenital anomalies in 1 patient $(0.5 \%)$, and miscellaneous lesions in 19 patients $(9.5 \%)$ (Tables 3-5).

\section{Distribution of Clinical Patterns According to Age}

Inflammatory dermatoses, infections, and benign abnormalities were prevalent in all age groups, with a clustering in 21-30 years (42\%). Ages below 20 accounted for $22.5 \%$ of the patients. Among children younger than 10 years, infections were significantly more common $(\mathrm{p}<0.05)$ than in other groups. Ten percent of the patients were in the geriatric age group (60 years or older), in which inflammatory dermatoses were more common (Table 6).

\section{DISCUSSION}

Non-venereal genital dermatoses are of paramount importance yet considered orphan diseases. Because of the intimate nature of the problem, patients are frequently restrained about discussing these issues with their healthcare providers. In many cases, patients opt for over-the-counter remedies. Additionally, it is important to consider the possibility of sexually transmitted diseases and urological or gynecological disorders, and refer accordingly. Combined multispecialty clinics may be useful for these patients $[10,11]$.

A variety of non-venereal genital conditions were observed among the patients in our study. Among the 200 patients, 54 different types of non-venereal dermatoses were prevalent, with 48 different types in males and 26 in females. The prevalence of non-venereal genital dermatoses accounted for $0.93 \%$ in our study. In a study by Degboe et al. from Benin [12], the prevalence was $1.3 \%$. However, in a study by Karthikeyan et al. from India [13], the overall prevalence of non-venereal dermatoses (only male patients) was exceptionally low, that is, 1.4 per thousand.

The mean age group of the patients in our study was 29.5 years ( $\mathrm{SD}=15.5$ years), ranging from two months to 81 years. This is similar to a study by Acharya et al. [14]. Most of the patients in our study belonged to the age group of $21-30$ years $(30 \%)$. This could have been due to the highly active population group who visited the hospital. This finding is similar to a study by Karthikeyen et al. [13], Saraswat et al. [15], and AlYasin et al. [16]. The analysis of the results from our series showed the occurrence of genital dermatosis in both sexes, with a slight male predominance at a male-to-female ratio of 2.7:1. Male predominance was also reported by Degboe et al. [12], Acharya et al. [13], Shinde et al. [17], Puri et al. [18], and Lakjiri et al. [19].

There was almost an equal percentage of married $(50 \%)$ and unmarried patients $(49.5 \%)$ in our study, which is similar to a study by Saraswat et al. [15], in which $52 \%$ were married and $48 \%$ were unmarried, yet different from a study by Singh et al. [20], Puri et al. [18], and Pathak et al. [7], in which $81.6 \%, 96 \%$, and $67.6 \%$ were married, respectively. This is in contrast with the general perception that marriage and sexual exposure are associated with genital dermatoses [21].

As for the common presenting complaints in our study, itching was the most common, occurring in $46 \%$ of the 
Table 3: Clinical patterns of non-venereal genital dermatoses

\begin{tabular}{lccc}
\hline Diagnosis & \multicolumn{2}{c}{ Sex } & Total \\
\cline { 2 - 3 } & Male & Female & $(\mathbf{n}=\mathbf{2 0 0})$ \\
\hline A. Inflammatory dermatoses & 48 & 35 & 83 \\
B. Infective dermatoses & 35 & 12 & 47 \\
a. Fungal & 10 & 5 & 15 \\
b. Viral & 5 & 3 & 7 \\
c. Bacterial & 2 & 4 & 6 \\
d. Parasite (scabies) & 18 & 1 & 19 \\
C. Benign and normal variants & 38 & 6 & 44 \\
D. Trauma or artefacts & 4 & 0 & 4 \\
E. Premalignant or malignant lesions & 1 & 1 & 2 \\
F. Congenital abnormalities & 1 & 0 & 1 \\
G. Miscellaneous & 19 & 0 & 19 \\
Vitiligo & 13 & 0 & 13 \\
Peyronie's disease & 2 & 0 & 2 \\
Melanocytic nevi & 1 & 0 & 1 \\
Lymphedema & 1 & 0 & 1 \\
Hydrocele & 2 & 0 & 2 \\
Total & 146 & 54 & 200 \\
\hline
\end{tabular}

Table 4: Patterns of inflammatory dermatoses

\begin{tabular}{lccc}
\hline Inflammatory Dermatoses & \multicolumn{2}{c}{ Sex } & Total \\
\cline { 2 - 3 } & Male & Female & \\
\hline a. Drug reactions & 11 & 12 & 23 \\
b. Eczema & 11 & 2 & 13 \\
c. Immuno-bullous disorders & 4 & 1 & 5 \\
d. Behçet's disease & 1 & 2 & 3 \\
e. Hailey-Hailey disease & 1 & 0 & 1 \\
f. Lichen planus & 4 & 0 & 4 \\
g. Lichen simplex chronicus & 2 & 3 & 5 \\
h. Lichen sclerosus atrophicus & 3 & 9 & 12 \\
i. Lichen nitidus & 2 & 0 & 2 \\
j. Psoriasis & 2 & 2 & 4 \\
k. Exfoliative dermatitis & 4 & 2 & 6 \\
I. Urticaria & 0 & 1 & 1 \\
m. Systemic lupus erythematosus & 0 & 1 & 1 \\
n. Small vessel vasculitis & 1 & 0 & 1 \\
o. Zoon's balanitis & 2 & 0 & 2 \\
Total & 48 & 35 & 83 \\
\hline
\end{tabular}

Table 5: Patterns of benign dermatoses

\begin{tabular}{lccc}
\hline Benign and Normal Variants & \multicolumn{2}{c}{ Sex } & Total \\
\cline { 2 - 3 } & Male & Female & \\
\hline Pearly penile papules & 15 & 0 & 15 \\
Epidermoid cysts & 9 & 0 & 9 \\
Angiokeratoma & 4 & 1 & 5 \\
Phimosis & 5 & 0 & 5 \\
Bartholin cysts & 0 & 2 & 2 \\
Fordyce spots & 1 & 1 & 2 \\
Pigmented raphe & 1 & 0 & 1 \\
Paraphimosis & 1 & 0 & 1 \\
Acrochordon & 1 & 0 & 1 \\
Mucosal tags & 0 & 1 & 1 \\
Preputial cysts & 1 & 0 & 1 \\
Verrucous epidermal nevi & 0 & 1 & 1 \\
Total & 38 & 6 & 44 \\
\hline
\end{tabular}

patients. Most of the studies reported itching as the common symptom $[17,18]$. Itching was also the most common presenting complaint in studies from Nepal in female patients [8].

Since the genital surface is also part of the skin, lesions in the genitalia are closely related to other mucocutaneous sites [2]. Our study found that dermatoses involving the genitalia comprised only 107 (53.5\%), and the remaining showed involvement of the non-genital sites. $(\mathrm{p}=0.02)$. A similar study done on females found genital involvement in only $64 \%$, oro-genital involvement in $8 \%$, and oro-genital skin involvement in $28 \%$ of the patients $[20,22]$. The significance of the involvement behind the different sites is that genital dermatoses may be accompanied by dermatoses on other sites and vice versa.

Inflammatory dermatoses were the most common, followed by infections. Among inflammatory dermatoses, drug reactions (11.5\%) comprised the most common ones, followed by eczema (6.5\%). Inflammatory dermatoses were also the most common in a study by Shinde et al. [17], Puri et al. [18], and Gurumayum et al. [22], whereas infections comprised the major dermatoses in a study by Degboe et al. [12] and Acharya et al. [13]. Infections were significantly more frequent among children and adolescents, which is similar to a study by Devi et al. [23].

As for the patient's sex, the common diseases in males were scabies in 18 (12\%), infections in $16(10.9 \%)$, and pearly penile papules in $15(10.2 \% \%)$. In a study by Saraswat et al. [15], the common disorders in males were vitiligo $(18 \%)$, pearly penile papules (16\%), and fixed drug eruption (12\%). Khoo et al. [24] in Singapore found pearly penile papules (14.3\%) as the most common non-venereal dermatoses in males. The most common genital dermatosis in females was lichen sclerosus atrophicus in $16.7 \%$, followed by toxic epidermal necrolysis and candidiasis. Joshi et al. [8] from Nepal also reported lichen sclerosus atrophicus and candidiasis as the most common genital problem in female patients. Lichen sclerosus atrophicus, candidiasis, and vitiligo were common in a study by Puri et al. [18], Singh et al. [20], and Babu et al. [25].

Candidiasis was the most common infectious cause of genital dermatoses, which was seen in $9(4.5 \%)$ patients. It was also seen as a common infectious cause by Pathak et al. [7], Joshi et al. [8], Puri et al. [18], and Gurumayum et al. [22]. Candidiasis was also presented in sites adjacent to the genitalia involving the abdomen, thighs, and umbilicus, similarly to other studies [8,22]. 
www.odermatol.com

Table 6: Clinical patterns according to age

\begin{tabular}{|c|c|c|c|c|c|c|c|c|}
\hline \multirow[t]{2}{*}{ Diagnosis } & \multicolumn{7}{|c|}{ Age (yrs.) } & \multirow{2}{*}{$\begin{array}{c}\text { Total } \\
(n=200)\end{array}$} \\
\hline & $0-10$ & $11-20$ & $21-30$ & $31-40$ & $41-50$ & $51-60$ & $60+$ & \\
\hline Inflammatory conditions & 8 & 8 & 30 & 13 & 9 & 8 & 7 & 83 \\
\hline Infections and infestations & 12 & 7 & 21 & 4 & 1 & 1 & 1 & 47 \\
\hline $\begin{array}{l}\text { Benign or } \\
\text { normal variants }\end{array}$ & 1 & 6 & 25 & 7 & 5 & 0 & 0 & 44 \\
\hline Premalignant and malignant & 0 & 0 & 0 & 0 & 2 & 0 & 0 & 2 \\
\hline Congenital abnormalities & 0 & 1 & 0 & 0 & 0 & 0 & 0 & 1 \\
\hline Trauma and artefacts & 0 & 1 & 1 & 2 & 0 & 0 & 0 & 4 \\
\hline Miscellaneous & 0 & 1 & 7 & 4 & 3 & 3 & 1 & 19 \\
\hline Total $(n)$ & 21 & 24 & 84 & 30 & 20 & 12 & 9 & 200 \\
\hline Total (\%) & 10.5 & 12 & 42 & 15 & 10 & 6 & 4.5 & 100 \\
\hline
\end{tabular}

Other fungal infections were dermatophytoses and pityriasis versicolor.

Bacterial contribution to genital dermatoses involved 6 patients (3\%). Gurumayum et al. [22] observed folliculitis $(16 \%)$ as the most common dermatosis. Bacterial infections were described as the common cause of genital dermatoses in studies by Singh et al. [20] and Pathak et al. [7].

In our study, $11.5 \%$ of various drug reactions were encountered, which were the common causes of inflammatory dermatoses. The most common drug reaction with genital involvement was Stevens-Johnson syndrome/toxic epidermal necrolysis (SJS/TEN) in $9 \%$ of the patients, fixed drug eruptions in $1.5 \%$, and a case of exanthematous drug eruption and drug rash with eosinophilia and systemic symptoms (DRESS). Niemeijer et al. [26] reported genital involvement of SJS/TEN in $70 \%$ of patients. Three cases of fixed drug eruptions were reported in a study by Karthikey et al. [14] .

Lichen sclerosus atrophicus (LSA) was observed in $12(6 \%)$ patients, where females significantly outnumbered males $(\mathrm{p}=0.0001)$. Singh et al. [20] found 26 cases $(21.7 \%)$ of LSA in females. Puri et al. [18] found LS only in females and presented it as a common genital dermatosis (15\%). Fischer et al. [27] reported $18 \%$ of prepubertal girls with LSA.

The genital skin is sensitive to allergens. Eczemas were present in $6.5 \%$ of the patients as scrotal eczema and vulval eczema. Singh et al. [20] encountered two cases of irritant dermatitis. Karthikeyan et al. [14] observed 13 cases of scrotal dermatitis. Gurumayum et al. [22] reported three cases of irritant contact dermatitis.

Pearly penile papules (PPP) were seen in $15(7.5 \%)$ of the patients. Puri et al. [18] and Gurumayum et al. [22] reported $10 \%$ and $3 \%$ of patients with PPP, respectively.
Similarly to our findings, Khoo et al. reported pearly penile papules as a common non-venereal condition in sexually transmitted disease (STD) clinics, occurring in $14 \%$ of the population [24].

Genital psoriasis is a rare inflammatory dermatosis usually occurring as part of a generalized disease presentation. In our study, we found that $2 \%$ of the patients had genital psoriasis, a rate that is comparable to the frequency of $2-6 \%$ mentioned in the literature $[19,23]$.

No primary malignant lesion was encountered in our study, yet a secondary lesion from an ovarian malignancy was noted in a female. However, other studies reported some cases of SCC and verrucous carcinoma [18,23]. The reason behind a smaller number of premalignant and malignant lesions of the genitalia may be due to the study population confined to the dermatology department and a smaller prevalence of the disease among the study population.

\section{Limitations of the Study}

Because our study was hospital-based, it was not completely representative of the situation in the community. We studied no risk factors for these dermatoses. A limited sample size might have led to the exclusion of rare diseases in our study population.

\section{CONCLUSIONS}

The prevalence of non-venereal genital conditions may be only the tip of the iceberg in terms of the actual number of patients who suffer from such problems. Their etiologies are often multifactorial and clinical patterns are diverse, with manifestations of systemic diseases, anatomical variants, and inflammatory, infective, and neoplastic conditions. This demands awareness and current and timely treatment. 


\section{ACKNOWLEDGMENTS}

The authors would like to thank all participants enrolled in their study and all faculty, resident, and staff members of the Department of Dermatology and Venereology, Institute of Medicine, for their cooperation in conducting the study.

\section{Statement of Human and Animal Rights}

All the procedures followed were in accordance with the ethical standards of the responsible committee on human experimentation (institutional and national) and with the 2008 revision of the Declaration of Helsinki of 1975.

\section{Statement of Informed Consent}

Informed consent for participation in this study was obtained from all patients.

\section{REFERENCES}

1. Khaitan BK. Non-venereal diseases of genitalia. In: Sharma VK, editor. Sexually Transmitted Diseases and AIDS. $1^{\text {st }}$ edn. New Delhi: Viva books Pvt Ltd; 2003. pp. 413-421.

2. Griffiths C, Barker J, Bleiker T, Chalmers D, Bunker CB, Porter W. The genital, perianal and umbilical regions. In: Griffiths C, Barker J, Bleiker T, Chalmers D, eds. Rook's Textbook of Dermatology. $9^{\text {th }}$ ed. Wiley-Blackwell, 2016.

3. Conforti C, Giuffrida R, Di Meo N, Longone M, Vichi S, Colli C, et al. Benign dermatoses of the male genital areas: A review of the literature. Dermatol Ther. 2020;33:e13355.

4. Sadownik LA, Koert E, Maher C, Smith KB. A qualitative exploration of women's experiences of living with chronic vulvar dermatoses. J Sex Med. 2020;17:1740-50.

5. Ryan C, Sadlier M, De Vol E, Patel M, Lloyd AA, Day A, et al. Genital psoriasis is associated with significant impairment in quality of life and sexual functioning. J Am Acad Dermatol. 2015;72:978-83.

6. Gabrielson AT, Le TV, Fontenot C, Usta M, Hellstrom WJG. Male genital dermatology: A primer for the sexual medicine physician. Sex Med Rev. 2019;7:71-83.

7. Pathak D, Agrawal S, Dhali TK. Prevalences of and risk factors for vulvar diseases in Nepal: A hospital-based study. Int J Dermatol. 2011;50:161-7.

8. Joshi S, Shrestha S, Joshi A. Clinico-epidemiological profile of women with non-venereal vulval diseases: A hospital-based observational study. NJDVL. 2019;17:32-8.

9. Gyawalee M, Pokhrel D. Pattern of sexually transmitted infections and sexual behavior in patients with genital symptoms. NJDVL. 2016;12:20-7.

10. Ascott A, Chinthapalli S, Gibbon K. Unifying clinical care between specialties: A model for genital disease. J R Soc Med.
2017;110:177-82.

11. Cheung ST, Gach JE, Lewis FM. A retrospective study of the referral patterns to a vulval clinic: Highlighting educational needs in this subspeciality. J Obstet Gynaecol. 2006;26:435-7.

12. Degboe B, Atadokpede F, Adegbidi H, Saka B, Akpadjan F, d'Almeida C, et al. [Epidemiological and clinical characteristics of anogenital dermatoses in the department of dermatologyvenereology in Cotonou, Benin]. Med Sante Trop. 2014;24:416-9.

13. Acharya KM, Ranpara H, Sakhia JJ, Kaur C. A study of 200 cases of genital lesions of non-venereal origin. Indian J Dermatol Venereol Leprol. 1998;64:68-70.

14. Karthikeyan K, Jaisankar TJ, Thappa DM. Non-venereal dermatoses in male genital region-prevalence and patterns in a referral centre in South India. Indian J Dermatol. 2001;46:18-22.

15. Saraswat PK, Garg A, Mishra D, Garg S. A study of pattern of nonvenereal genital dermatoses of male attending skin OPD at a tertiary care center. Indian J Sex Transm Dis AIDS. 2014;35:129-34.

16. Al-Yasin ZT. The frequency of symptomatic vulval disease: A gynecological's perspective. MJBU. 2009;27:104-7.

17. Shinde G, Popere S. A clinical study of non-venereal genital dermatoses of adult in a tertiary care center. Int J Biomed Adv Res. 2017;8:168-73.

18. Puri N, Puri A. A study on non-venereal genital dermatoses in North India. Our Dermatol Online. 2013;4:304-7.

19. Lakjiri S, Meziane M, Elloudi S, Sy O, Nejjari C, Mernissi FZ. [Genital dermatoses: Epidemiological and clinical profile]. Pan Afr Med J. 2014;18:240.

20. Singh N, Thappa DM, Jaisankar TJ, Habeebullah S. Pattern of nonvenereal dermatoses of female external genitalia in South India. Dermatol Online J. 2008;14:1.

21. Vinay N, Ranugha PSS, Betkerur JB, Shastry V, Ashwini PK. Non-venereal genital dermatoses and their impact on quality of life: A cross-sectional study. Indian J Dermatol Venereol Leprol. 2021:1-6.

22. Gurumayum M, Shivakumar V, Okade R. Non-venereal female genital dermatoses: A clinical study. JMSCR. 2014;2:2864-73.

23. Devi VN, Balachandrudu P. Prevalence and patterns of genital dermatoses in children. Int J Sci Res. 2015;4:1833-9.

24. Khoo LS, Cheong WK. Common genital dermatoses in male patients attending a public sexually transmitted disease clinic in Singapore. Ann Acad Med Singapore. 1995;24:505-9.

25. Babu AR, Shivakumar V, Prasad AM. A clinical study of non-venereal genital dermatoses in women in a rural setup. Int $J$ Med Public Health. 2020;10:29-33.

26. Niemeijer IC, van Praag MC, van Gemund N. Relevance and consequences of erythema multiforme, Stevens-Johnson syndrome and toxic epidermal necrolysis in gynecology. Arch Gynecol Obstet. 2009;280:851-4.

27. Fischer GO. Vulval disease in pre-pubertal girls. Australas J Dermatol. 2001;42:225-36.

Vikash Paudel, et al. This is an open-access article distributed under the terms of the Creative Commons Attribution License, which permits unrestricted use, distribution, and reproduction in any medium, provided the original author and source are credited.

Source of Support: Nil, Conflict of Interest: None declared. 